best and often absent. We now know that the Commission currently has experience of 57 patients assessed for psychosurgery ${ }^{4}$ and even this experience is divided between several of the Commission's doctors. The patients are seen only once and there is no clinical experience of trying alternative forms of therapy and of post-operative rehabilitation and follow-up. How can it be reasonable that these decisions over-ride the opinions of the multidisciplinary staff of this Unit, as pointed out by Dr Turner in his letter? In more general terms, how can psychiatry ever advance if the clinical policies of an innovative unit are dominated by two retired consultants and a psychogeriatrician?

We agree with the Commission that patients should have available all reasonable information about their illness and its management, and their rights should at all times be protected. To this end, when our recommendation to operate has been over-ruled by commissioners, we intend to encourage the patients and their families, with the permission of the referring doctors, to obtain detailed reasons from the Commission about the decision and about the doctor involved in the decision, and if appropriate, to ask for an independent opinion acceptable to the patient and his medical advisers, as is the traditional medical right of patients.

We would like to make clear that the advent of the Commission has not changed our clinical policies. It is not our experience that our psychosurgical practice has been curtailed to any great extent by the Commission although there have been difficulties with individual patients. We hope that consultants will not feel that the presence of the Commission inhibits them from referring patients for our assessment, if they wish to do this. Indeed, it seems to us of paramount important that the very distressed patients who we may be able to help will not be denied adequate treatment because of the preseumed antagonism of the Commission. After all, our experience has been that medical commissioners have agreed to operations in the case of 34 of our patients out of 39 referred to them up to the end of 1985.

The Geoffrey Knight Psychosurgical Unit

Paul Bridges

Brook General Hospital

London SE18

REFERENCES

'Turner, P. (1986) Mental Act 1983, Bulletin of the Royal College of Psychiatrists, 10, 53.

${ }^{2}$ Berdoces, P. K. (1984) Psychosurgery and the Mental Health Act Commission. Bulletin of the Royal College of Psychiatrists, 8, 146-148.

${ }^{3}$ Thompson, C. (1985) An open letter to Lord Colville. Bulletin of the Royal College of Psychiatrists, 9, 100.

4The First Biennial Report of The Mental Health Act Commission 1983-85. London: HMSO, October 1985.

\section{Senior registrars' posts in old age psychiatry} DeAR Strs

Blessed has reviewed the declared need for more consult- ants to develop and run services for the elderly and has provided evidence that the number of suitable training posts at senior registrar level is increasing ${ }^{1}$. Among the difficulties facing manpower planners at present is ignorance of the subsequent careers of trainees who pass through these posts. We have reviewed the careers of doctors who have taken advantage of the training posts identified in an earlier survey $^{2}$ to determine the yield from these posts during the years 1980-1986, by gathering information from the named trainers (See Table I). In particular we have been interested to clarify differences in outcome when trainees applied directly to these posts compared with rotation as part of a general psychiatry training scheme of other modes of appointment:

All the posts offering direct appointment to a training in old age psychiatry offered full-time training in the sense that Blessed has defined. All but one of the 16 senior registrars who have progressed to consultant appointments are dedicated to old age.

Not all of the 'rotation posts' offer full-time training and there is a trend for those offering more training to achieve a greater yield of career psychogeriatricians (See Table II). Nevertheless the yield is less than 1 in 3, the majority of trainees becoming general psychiatrists and only a minority of them having formal sessional commitments to services for the elderly.

Research posts, part-time posts (PM(79)3) and a special secondment were much more likely to lead to careers in old age psychiatry. In the main those trainees/researchers had made their intentions clear in organising their own training.

If the yield from newly established posts is similar to that for those that have been available up to now, the creation of more posts which are filled by rotation from within general psychiatry training schemes will be disappointingly low and a very large number of such posts will be needed to fill predicted requirements at consultant level. This may be an ideal way to respond to the problem and would have the benefit that many general psychiatrists would have a greater working knowledge of the disorders of old age and the services available to manage them. The alternative of dedicating more posts to old age psychiatry from appointment is likely to produce more career-psychogeriatricians from each post and trainees should have the opportunity to achieve a more comprehensive specialist training than is possible in a one year rotated attachment.

It seems probable that the best course is a middle-road, with some posts offered as part of a general psychiatry rotation reaching out to trainces who are interested but undecided, and others responding to the wishes of those who are committed to the work but who would prefer a wider and deeper exposure to the subspeciality by direct appointment.

DAVID JOLLEY RUTH HORTON

Psychogeriatric Unit

Withington Hospital, Manchester 
Our thanks are due to Drs Blessed, Wattis, Arie, Jones, Conway, Levy, Fottrell, Godber, Langley, Philpott, Hodgson, Bergmann, Hemsi, Mann, Young, Murphy, Kellett, Boyd, Jacques, Phanjoo, Simons, Walker, Gardner, Greenwood, Spotswood, McDonald, Robinson, Pitt, Bromham, Fairburn, Lister, Halim, Williams for providing information about their trainees.
REPERENCES

${ }^{1}$ BLessed, G. (1986) Survey into the availability of higher specialist training in the psychiatry of old age. Bulletin of the Royal College of Psychiatrists, 10, 88-89.

${ }^{2}$ WATtIS, J. \& ARIE, T. (1984) Further developments in psychogeriatrics in Britain. British Medical Journal, 289, 778.

TABLE I

The yield of Senior Registrar posts in Old Age Psychiatry 1980-1986

\begin{tabular}{lrrrrrrr}
\hline Appointment Mode & \multicolumn{7}{c}{ Career Outcome } \\
\hline & G & PG & G/PG & Rtd & C & Still Training & Total \\
& 1 & 15 & - & - & 16 & 5 & 21 \\
Direct & 49 & 25 & 13 & 1 & 88 & 16 & 104 \\
Rotation & 2 & 5 & 1 & - & 8 & 1 & 9 \\
PM 79/3 & - & 4 & - & - & 4 & - & 4 \\
Research & - & 1 & - & - & 1 & - & 1 \\
Secondment & 52 & 50 & 14 & 1 & 117 & 22 & 139 \\
\hline Total & & & & & & &
\end{tabular}

G = General Psychiatrist

$\mathbf{P G}=$ Psychogeriatrician full-time or major responsibility for the services to the elderly G/PG = General Psychiatrist with some sessions, 5 or less, devoted to the elderly Rtd $=$ Retired

$\mathrm{C}=$ Career post achieved

TABLE II

The yield of Sentor Registrar posts offering rotation through Psychiatry of Old Age

\begin{tabular}{lrrrrrrc}
\hline & G & PG & G/PG & Rtd & C & Still Training & Total \\
A & 28 & 15 & 9 & 1 & 53 & 8 & 61 \\
B & 8 & 3 & 3 & - & 14 & 4 & 18 \\
C & 8 & 3 & 1 & - & 12 & 3 & 15 \\
D & 5 & 4 & - & - & 9 & 1 & 10 \\
\hline Total & 49 & 25 & 13 & 1 & 88 & 16 & 104 \\
\hline
\end{tabular}

$A=12$ months or more, 5 sessions or more per week

$B=$ Less than 12 months, 5 sessions or more per week

$C=$ Less than 12 months, less than 5 sessions per week

$\mathrm{D}=$ Not established posts, occasional holders

\section{Kraepelin Gold Medal}

The Kraepelin Gold Medal was awarded to Sir Martin Roth, Emeritus Professor of Psychiatry, University of Cambridge, at a special ceremony before an international audience at the Max Planck Institute in Munich on 29 May 1986. The Gold Medal was created shortly after the death of Kraepelin in 1926 to commemorate his life's work and the tradition he established in psychiatry, and is awarded for psychiatric research. Recipients are chosen by an international panel of scientific workers in psychiatry. Sir Martin is the first British recipient; the previous 11 awards have gone to scientists from Denmark, Germany, Switzerland, and the United States. 